\title{
Association Between Physical Activity and Osteoarthritis of Knee with Quality of Life in Community-Dwelling Older Adults
}

\author{
Nachalida YUKALANG ${ }^{\mathrm{a}, \mathrm{b}}$, Niruwan TURNBULL ${ }^{\mathrm{a}, \mathrm{b}}$, Wisit THONGKUM ${ }^{\mathrm{a}, \mathrm{b}}$, Adisorn \\ WONGKONGDECH ${ }^{\mathrm{a}}$, Kukiat TUDPOR ${ }^{\mathrm{a}, \mathrm{b}, 1}$ \\ ${ }^{a}$ Faculty of Public Health, Mahasarakham University, Thailand \\ ${ }^{\mathrm{b}}$ Public Health and Environmental Policy in Southeast Asia Research Unit \\ (PHEP-SEA), Mahasarakham University, Thailand
}

\begin{abstract}
Older adults are relatively physically active compared to other age group. A lack of physical activity (PA) can cause chronic diseases including osteoarthritis of knee (OA knee) and might eventually reduce quality of life (QOL). This present study was aimed to investigate association between levels of PA and OA knee with levels of QOL in community-dwelling older adults. One thousand and sixty-seven community-dwelling older persons were recruited to this descriptive study. PA activity questionnaire was invented. Standardized Oxford knee score and World Health Organization's Quality of Life scale (WHOQOL-BREF) were used to measure OA knee and QOL levels. Results showed that levels of PA in older adults were significantly associated with levels of OKS $\left(\chi^{2}=78.565\right.$, P-value $\left.<.001\right)$ and levels of OA knee in older adults were significantly associated with levels of overall QOL $\left(\chi^{2}=57.738\right.$, P-value $\left.<.001\right)$. Pearson's correlation also showed interrelation among PA, OA knee, and QOL. In conclusion, PA, OA knee, and QOL are interrelated. Therefore, close monitoring and design of proper PA activity should be implemented in community-dwelling older adults with OA knee.
\end{abstract}

Keywords. Osteoarthritis of knee, Older adults, Physical activity, Quality of life, Personal health

\section{Introduction}

Older adults are the least physically active age group with less than $25 \%$ performing regular physical activity (PA) [7]. A lack of PA has been considered as an important factor in etiology of diabetes, hypertension, cancer, and osteoarthritis [6]. Osteoarthritis of knee (OA knee) is a leading cause of global disability and is associated with significant economic costs [3]. The incidence of OA knee increases with advancing age, especially in the people of age above 60 years old [8]. OA knee leads to knee joint instability, postural sway, and risk of fall [20]. The Oxford Knee Score (OKS) is well correlated increasing age [4]. Quality of life (QOL) is an individual's perception of position in life in the context of the culture and value systems in relation to one's goals, expectations, standards and concerns [13]. The World Health Organization's Quality of Life scale (WHOQOL-BREF) is a widely used, reliable, valid, and self-report questionnaire which

\footnotetext{
${ }^{1}$ Corresponding Author: Kukiat Tudpor, Faculty of Public Health, Mahasarakham University, Kham Rieng, Kantarawichai, Maha Sarakham, Thailand 44150; E-mail: kukiat.t@msu.ac.th
} 
assesses 4 domains of QOL in terms of physical health, psychological health, social relationships, and environment [22]. Relationship between PA and QOL or OA knee and QOL have been extensively reported $[1 ; 11 ; 16 ; 17 ; 19 ; 23]$. However, interrelationship among these three domain were still elusive. Therefore, this present study was aimed to investigate association between levels of PA and OA knee with levels of QOL in community-dwelling older adults.

Table 1 Questionnaires of physical activity over the last one month

\begin{tabular}{l}
\hline \\
\hline 1.You exercise $3-5$ times a week. \\
2.You exercise at least 30 minutes at a time. \\
3. You can walk until you feel moderately tired or breathe a little harder than usual, but can still talk to others \\
until the end of the sentence at least $3-5$ days a week \\
4. You can jog until you feel moderately tired or breathe a little harder than usual, but can still talk to others \\
until the end of the sentence at least 3- 5days a week \\
5.You warm up 5- 10minutes before exercising or playing sports. \\
6.You stretch after exercising or playing sports for 5-10 minutes. \\
7.You do housework such as sweeping and mopping the house by yourself. \\
8.You walk up and down stairs by yourself.
\end{tabular}

\section{Methods}

\subsection{Study design and participants}

One thousand and sixty-seven community-dwelling older persons from Nonghi district, Roi Et, Thailand, voluntarily participated in this descriptive research. Inclusion criteria was age $\geq 60$ years old. All procedures have been voted by 2 reviewers, approved by the Ethics Committee for Research Subjects of Roi Et Provincial Public Health Office, Ministry of Public Health and endorsed by the chairperson Mr.Pitak Payuha (No.COE 063256).

\subsection{Questionnaires}

The 8-item questionnaire of physical activity (Table 1) was approved by index of itemobjective congruence (IOC), a procedure used in test development for evaluating content validity at the item development stage. Only the items with IOC scores $\geq 0.5$ were qualified for the questionnaire. The items with Cronbach's $\alpha$ (test score reliability coefficient) $\geq 0.7$ were acceptable and used in the questionnaire. Each item was scored 1-4 (never, sometimes, frequently, and always, respectively), given total score of 32 . The total score was further ranked as physical activity levels from low, moderate, and high $(<17,17-24$, and $\geq 25$, respectively). The Oxford Knee Score (OKS) and WHOQOLBREF are standardized questionnaires $[12 ; 13]$. The WHOQOL-BREF consists of 4 subscales with 26 items that measure different health concepts. Responses are rated from 1 (very poor/very dissatisfied/not at all) to 5 (very good/very satisfied/completely). The total score ranging from $0-100$ is calculated by averaging all item responses. Score $\geq 60$ and $<60$ indicate good and poor QOL, respectively [18]. 


\subsection{Statistical Analyses}

The data was employed descriptive statistics, then the association of categorical and continuous data were analyzed by $\chi^{2}$ and Pearson's correlation tests (a measure of linear correlation between two sets of data). The level of statistical significance was $p<0.05$. All data were analyzed by SPSS Statistics version 18.

Table 2 Personal characteristics of participants

\begin{tabular}{|c|c|c|}
\hline Characteristics & Number & Percentage \\
\hline \multicolumn{3}{|l|}{ Sex } \\
\hline Male & 425 & 39.8 \\
\hline Female & 642 & 60.2 \\
\hline \multicolumn{3}{|l|}{ Age (years old) } \\
\hline $60-69$ & 529 & 54.3 \\
\hline $70-79$ & 315 & 32.3 \\
\hline$>80$ & 130 & 13.3 \\
\hline \multicolumn{3}{|l|}{ Educational level } \\
\hline Primary school & 7 & 0.7 \\
\hline Secondary school & 973 & 92.7 \\
\hline High school & 53 & 5.0 \\
\hline Diploma & 5 & 0.5 \\
\hline Bachelor and higher & 12 & 1.1 \\
\hline \multicolumn{3}{|l|}{ Marital status } \\
\hline Single & 43 & 4.1 \\
\hline Married & 609 & 58.2 \\
\hline Divorced/widowed & 364 & 34.5 \\
\hline Separated & 34 & 3.2 \\
\hline \multicolumn{3}{|l|}{ Average income per month } \\
\hline less than 5,000 baht & 964 & 90.4 \\
\hline $5,000-10,000$ baht & 82 & 7.7 \\
\hline $10,001-15,000$ baht & 8 & 0.8 \\
\hline More than 15,000 baht & 12 & 1.1 \\
\hline \multicolumn{3}{|l|}{ Body mass index level } \\
\hline Underweight & 644 & 60.8 \\
\hline Normal & 370 & 34.9 \\
\hline Overweight & 19 & 1.8 \\
\hline Obese & 26 & 2.5 \\
\hline \multicolumn{3}{|l|}{ Living status } \\
\hline Alone & 64 & 6.0 \\
\hline With spouse & 545 & 51.1 \\
\hline With children/grandchildren & 491 & 46.0 \\
\hline With other relatives & 33 & 3.1 \\
\hline
\end{tabular}

\section{Results}

3.1. Association between levels of physical activity and levels of OA knee

Personal characteristics of the participants are shown in Table 2. Results showed that the levels of PA of 1,067 older adults were significantly associated with levels of OKS $(\chi 2$ $=78.565$, P-value $<.001)$ (Table 3) .

Table 3 Association between levels of physical activity and levels of OA knee

\begin{tabular}{lcccccc}
\hline \multirow{2}{*}{ Physical activity level } & \multicolumn{7}{c}{ OA knee level } \\
\cline { 2 - 7 } & Excellent & Good & Moderate & Poor & $\boldsymbol{\chi}^{\mathbf{2}}$ & P-value \\
\hline High & 277 & 102 & 20 & 8 & 78.565 & $<.001$
\end{tabular}


$\begin{array}{lcccc}\text { Moderate } & 292 & 114 & 34 & 25 \\ \text { Low } & 83 & 51 & 28 & 33\end{array}$

\subsection{Association between Levels of OA Knee and Levels of Quality of Life}

Chi-square analysis showed that the levels of OA knee in older adults were significantly associated with levels of overall QOL $\left(\chi^{2}=57.738\right.$, P-value $\left.<.001\right)$ (Table 4).

Table 4 Association between levels of OA knee and levels of quality of life

\begin{tabular}{lcccc}
\hline \multirow{2}{*}{ OA knee level } & Good & \multicolumn{2}{c}{ Quality of life level } \\
& Poor & $\boldsymbol{\chi}^{\mathbf{2}}$ & P-value \\
\hline Excellent & 597 & 55 & 57.738 & $<.001$ \\
Good & 232 & 35 & & \\
Moderate & 75 & 7 & & \\
Poor & 40 & 26 & & \\
\hline
\end{tabular}
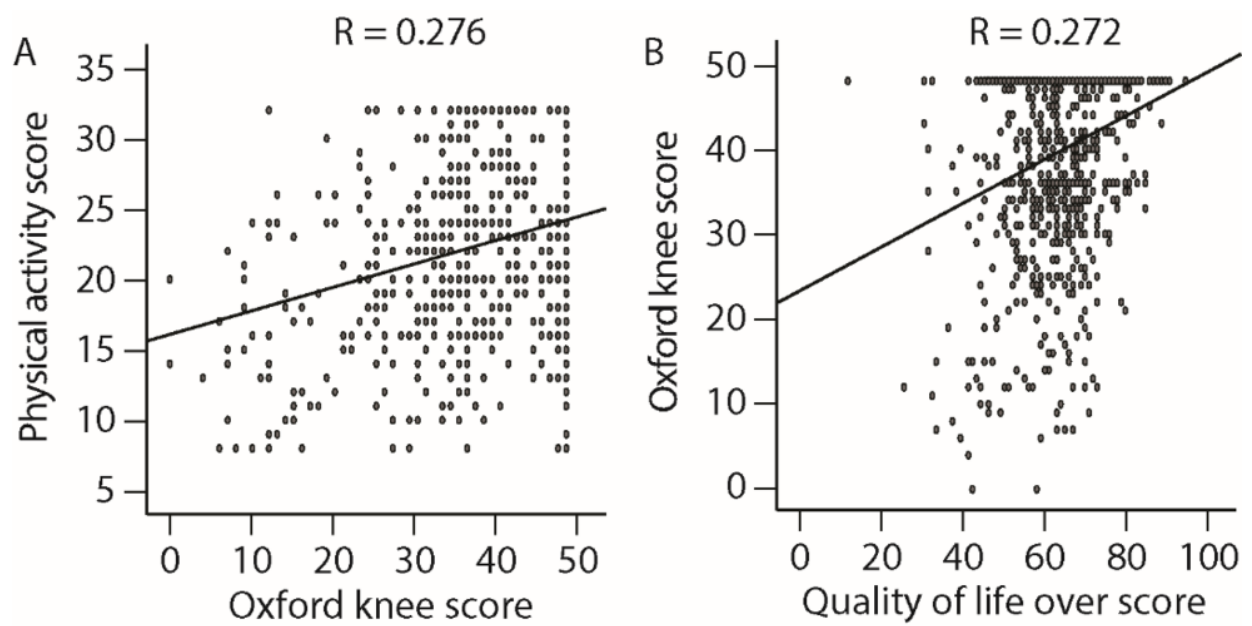

Figure 1. Pearson correlation between levels of physical activity and levels of OA knee (A); and levels of OA knee and levels of quality of life (B)

3.3 Correlation of scores of physical activity, osteoarthritis of knee, and quality of life Pearson's correlation analysis revealed that PA, OKS, and WHOQOL-bref scores were interrelated (Pearson's correlation $=.275$ and $.273 ; \mathrm{R}=0.276$ and 0.272 ; and $\mathrm{P}$-value $<$ .001 and .001, in PA vs OKS (Figure 1A) and OKS vs WHOQOL-bref (Figure 1B), respectively).

\section{Discussion}

\subsection{Characteristics of the Older Adults}

The characteristics studied were the sex of the participants, age, educational levels, marital status, income, body mass index, and living status. Most of the participants low educational levels and low income $(<5,000$ baht $)$. Low educational levels are inversely 
associated with higher QOL scores [15]. Similarly, low income is also associated low QOL level [10]. Therefore, low educational levels and low income found in this present study might be also the factors for low QOL.

\subsection{Physical Activity on Osteoarthritis of Knee}

This study revealed that PA levels were associated with OA knee levels. PA and OA knee levels are interrelated. Previous study showed that pain and disability in OA knee individuals limited an ability to perform exercises [17]. The PA with low impact on knee joints was reportedly beneficial to OA outcomes [19]. For OA knee patients, lowintensity exercise was recommended [16]. Therefore, it can be implied that appropriate level of PA might be able to prevent OA and the low-intensity with low impact on lower extremities should be implemented in older adult population.

\subsection{Osteoarthritis of Knee and Quality of Life}

Previous study showed that QOL was associated with self-reported disability in patients with OA knee $[1 ; 11 ; 23]$. OA knee also influences mental health and QOL [14]. Both conservative and surgical treatments were found to improve QOL in individuals with OA knee $[5 ; 9 ; 21]$. Interestingly, the older adults with OA knee reported their good QOL when they participated voluntary work and received proper recommendation for physical activity, especially resistance exercises [2]. This finding indicates that better QOL of the persons with OA knee can be obtained through appropriate design of physical activity.

\section{Conclusion}

In conclusion, physical activity, osteoarthritis of knee, and quality of life are interrelated. Therefore, in order to improve their quality of life, appropriate levels of physical activity should be tailor-made for individual needs of the older adults with osteoarthritis of knee. Further analysis for health service accessibility among osteoarthritis of knee patients as well as follow-up of its impacts on quality of life are of interest in the field of community public health and personalized health.

\section{References}

[1] Alkan BM, Fidan F, Tosun A, Ardicoglu O. Quality of life and self-reported disability in patients with knee osteoarthritis, Mod Rheumatol 2014; 24: 166-171.

[2] Alves JC, Bassitt DP. Quality of life and functional capacity of elderly women with knee osteoarthritis, Einstein (Sao Paulo) 2013; 11: 209-215.

[3] Araujo-Castillo RV, Culquichicon C, Solis Condor R. Burden of disease due to hip, knee, and unspecified osteoarthritis in the Peruvian social health insurance system (EsSalud), 2016, F1000Res 2020; 9: 238.

[4] Bremner-Smith AT, Ewings P, Weale AE. Knee scores in a 'normal' elderly population, Knee 2004; 11:, 279-282.

[5] Dervin GF, Stiell IG, Rody K, Grabowski J. Effect of arthroscopic debridement for osteoarthritis of the knee on health-related quality of life, J Bone Joint Surg Am 2003; 85: 10-19.

[6] Diet W. Nutrition and the prevention of chronic diseases. Report of a joint WHO/FAO expert consultation, WHO Technical report series 2003; 916: 34-38.

[7] Fakhouri TH, Ogden CL, Carroll MD, Kit BK, Flegal KM. Prevalence of Obesity Among Older Adults in the United States, 2007-2010, NCHS data brief 2012: 1-8. 
[8] Felson DT. Clinical practice. Osteoarthritis of the knee, N Engl J Med 2006; 354: 841-848.

[9] Fransen M, Crosbie J, Edmonds J. Physical therapy is effective for patients with osteoarthritis of the knee: a randomized controlled clinical trial, J Rheumatol 2001; 28: 156-164.

[10] Georgellis Y, Tsitsianis N, Yin YP. Personal values as mitigating factors in the link between income and life satisfaction: Evidence from the European Social Survey, Social Indicators Research 2009; 91: 329344.

[11] Kawano MM, Araujo IL, Castro MC, Matos MA. Assessment of quality of life in patients with knee osteoarthritis, Acta Ortop Bras 2015; 23: 307-310.

[12] Khatri K, Lakhotia D, Sharma V, Kiran Kumar GN, Sharma G, Farooque K. Functional Evaluation in High Energy (Schatzker Type V and Type VI) Tibial Plateau Fractures Treated by Open Reduction and Internal Fixation, Int Sch Res Notices 2014 (2014), 589538.

[13] World Health Organization. WHOQOL-BREF: introduction, administration, scoring and generic version of the assessment: field trial version, December 1996. In: World Health Organization, 1996.

[14] Park HM, Kim HS, Lee YJ. Knee osteoarthritis and its association with mental health and health-related quality of life: A nationwide cross-sectional study, Geriatr Gerontol Int 2020; 20: 379-383.

[15] Raggi A, Corso B, Minicuci N, Quintas R, Sattin D, et al. Determinants of Quality of Life in Ageing Populations: Results from a Cross-Sectional Study in Finland, Poland and Spain, PLoS One 2016; 11: e0159293.

[16] Regnaux JP, Lefevre-Colau MM, Trinquart L, Nguyen C, Boutron I, et al. High-intensity versus lowintensity physical activity or exercise in people with hip or knee osteoarthritis, Cochrane Database Syst Rev (2015), CD010203.

[17] Rosemann T, Kuehlein T, Laux G, Szecsenyi J. Osteoarthritis of the knee and hip: a comparison of factors associated with physical activity, Clin Rheumatol 2007; 26: 1811-1817.

[18] Silva PAB, Soares SM, Santos JFG, Silva LB. Cut-off point for WHOQOL-bref as a measure of quality of life of older adults, Revista de saude publica 2014; 48: 390-397.

[19] Sutton AJ, Muir KR, Mockett S, Fentem P. A case-control study to investigate the relation between low and moderate levels of physical activity and osteoarthritis of the knee using data collected as part of the Allied Dunbar National Fitness Survey, Ann Rheum Dis 2001; 60: 756-764.

[20] Tudpor K, Kanjanawanishkul K, Kam-Ard S, Intarak T, Traithip W, et al. Star Excursion Balance Test as an Exercise to Improve Static and Dynamic Balance in Community-Dwelling Persons with Unilateral Osteoarthritis of Knee, Editorial Advisory Board 2021; 15: 30.

[21] Usman Z, Maharaj SS, Kaka B. Effects of combination therapy and infrared radiation on pain, physical function, and quality of life in subjects with knee osteoarthritis: A randomized controlled study, Hong Kong Physiother J 2019; 39: 133-142.

[22] Vahedi S. World Health Organization Quality-of-Life Scale (WHOQOL-BREF): Analyses of Their Item Response Theory Properties Based on the Graded Responses Model, Iran J Psychiatry 2010; 5: 140-153.

[23] Xie Y, Yu Y, Wang JX, Yang X, Zhao F, et al. Health-related quality of life and its influencing factors in Chinese with knee osteoarthritis, Qual Life Res 2020; 29: 2395-2402. 